\title{
A Comparative Study on Physical and Comfort Properties of Yarns and Hand-woven Fabrics Produced from Virgin and Recycled Fibers
}

\author{
Dessalegn Awgichew*, Santhanam Sakthivel, Mekdes Gedlu, Meseret Bogale \\ Department of Textile Technology, Faculty of Textile and Apparel Fashion Technology, Ethiopian Technical \\ University, Addis Ababa 190310, Ethiopia \\ * Corresponding author email: desayemaryam@gmail.com \\ Received: 20 May 2021 / Revised: 16 September 2021 / Accepted: 07 November 2021 / Published: 23 December 2021
}

\begin{abstract}
Products produced from textile industries cannot meet the needs for human kind since the population of the world grows exponentially; due to this the recycling of textile materials has gained massive importance in textile and clothing sector. In this study, it was aimed to analyse recycled fibers effect on the yarn and hand loom fabrics as their proportion increases. For this purpose, OE rotor yarns produced by varying the recycled fibers proportion at $25 \%, 50$, and $75 \%$ and compared with $100 \%$ virgin cotton yarns. The physical and mechanical properties of the yarns such as unevenness, imperfections, hairiness, breaking force, elongation, were measured by Uster Tester 4 SX, Uster Zweigle Hairiness Tester 5, and Uster Tensorapid 3. Then after hand loom fabrics with plain and twill fabrics are produced from produced yarns of different recycled fiber proportions. The effects of recycled fiber proportion on produced hand-woven fabric properties such as pilling, abrasion resistance and air permeability were also evaluated. Results showed that yarns and fabrics produced from recycled fibers blended with virgin cotton are suitable for applications where the strength of yarns and fabric are less critical, but where unevenness, imperfections and handle properties required thus, hand loom fabrics Produced can suitably used for home furnishing applications like table cover, curtains, wall covers and pillow cases.
\end{abstract}

Keywords: Recycled fibers, OE-rotor spinning, Blended yarns.

\section{Introduction}

Textile production and consumption have increased significantly in recent years as just a result of increased global population and improving living conditions. Extreme production in the textile business is fueled in part by the fashion industry's belief that consumers require a new wardrobe for each season. This raises the rate of product exchange as well as the rate of fabric and waste generation [1]. This increases the exchange rate of products and the rate of fabric and waste production. The textile industry is one of the most important consumer goods sectors. However, the textile industry is accused of being one of the most polluting industries. Not only production but the use of textiles also produces waste. To combat this problem, the textile industry has taken many steps to reduce its negative contribution to the environment. One such step is to reuse fabrics [2]. Textile reuse benefits the environment and the economy by lowering the need for textile chemicals, reducing the demand for land, and lowering energy usage, as well as encouraging manufacturing. Suppliers increase the amount of recycling. Wasted on new products [3], the need for good waste management is due to rising costs and declining land acquisition and the depletion of natural resources. The purpose of this study was to analyze recycling garment waste fibers blended with virgin cotton for hand-woven practices [4]. The study shows that the proportional amount of virgin cotton with recycled fibers is the most influential parameter on properties of blended OE rotor spun yarns. According to Taher et al. [5] using $25 \%$ of recycled fiber does not affect the uniformity and appearance of rotor spun yarn. Based on their results 15\% and 25\% recycled waste ratio does not change the optimum

Copyright (C) 2021. The Author(s). Published by AIJR Publisher.

This is an open access article under Creative Commons Attribution-NonCommercial 4.0 International (CC BY-NC 4.0) license, which permits any non-commercial use, distribution, adaptation, and reproduction in any medium, as long as the original work is 
quality parameters of $\mathrm{OE}$ rotor yarn [6]. A large number of products are made from reclaimed fibers. Since, much of this fiber is re-spun into new yarns and manufactured to be woven, knitted, or vitally reused for non-woven production, upholstery materials, composite biomaterials, and others like garment linings and insulation materials [7]. Handwoven textiles are crafts that are made to communicate cultural values with objects [8]. The recycled fiber from garment wastes has fiber properties that are very essential for converting them into spun yarns and further to home furnishing applications. In this study the recycled fibers are spun into yarns by OE Rotor spinning machine, then yarn samples are undergone different property tests. After analyzing the yarn properties different fabric samples were developed by handweaving processes using a handloom. Samples developed from handloom are then subjected to be analyzed for weaving fabric properties such as pilling, abrasion resistance, tearing strength, and capability, GSM, and air permeability. Handmade cloths supply equally varied domain in apparel for furnishing applications with the domain of practical and artistic demand. Fabrics play an important role in controlling the environment of a home. The fabrics being the prime contributors provide texture, color and character. Fabric is the interior designer's pharmacy. It protects the interior color from fading and furnishing from deterioration by sunlight. It protects from sun glare and lends protection from night blackness at evening and from too early sun in the morning. Fabrics lend privacy to any degree that is needed [9]. Apart from various household activities there are some recycling-based crafts as well who probably immerged either to show creative expression or as a good and cheap substitute of raw materials. These recycling-based crafts are mainly female dominated activities and later became source of livelihood for their communities or tribes. Kantha work of Bengal can be considered as one of the oldest textile recycling practices in craft sector where excellent use of old muslin sarees is done as the base material to engrave beautiful hand embroidery using running stitch. According to Ray et al. [10], the nomadic Bakkarwal and Gujjar tribes of Jammu and Kashmir and Rajasthan use various recycling-based textile craft which is a part of their tradition, culture and to preserve the old textiles. Tribes belong to Jammu and Kashmir converts the old woolen felt blankets into handmade rugs by doing handmade needle work embroidery using acrylic yarns. Similarly, tribe belongs to Rajasthan do patch work, embroidery and mirror work to enhance the beauty of their textile products. Lot of accessories like cap, bags, wall hangings, mojaris (footwear), cushions etc. are also created by recycled textiles [11], [12]. Chindi durries of Haryana, where Durry weaving on pit looms is a very common practice at every next door of rural areas. Strips of old sarees, shawls, dupatta and other garments are used as raw material for rough weaving. The practical manufacturing technique was used to build, generate, and develop the pattern drafts in this work. This will obviously help in planning and seeing the design's appearance before it is woven on the cloth [13]. In this study the recycled fibers are spun into yarns by OE Rotor spinning machine, then yarn samples are undergone different property tests. After analyzing the yarn properties different fabric sample were developed by hand weaving processes using hand loom. Samples developed from hand loom are then subjected to be analyzed for weaving fabric properties such as pilling, abrasion resistance, Drapability, weight loss and air permeability according to the requirement. shortage of literature related to the tittle, in addition to this, due to the busy schedule of the machineries in the Etur textile factory it has been a problem on conducting this research work.

\section{Material and Methods}

The cutting waste is collected from the industry and it is then sorted by color, the cutted, shredded, carded and mechanical process to obtain reclaimed fibers. the obtained reclaimed fibers further sorted to for removing un opened fibers and other un wanted materials before mixing them with virgin fibers to make them suitable for carding process to produce slivers. Ne 20/1 OE-rotor yarns were produced from 100\% virgin cotton, $100 \%$ virgin cotton and recycled fiber blends with (75\%-25\%, 50\%-50\% and 25\%-75\%) blend ratios. Middle Awash cotton was used as virgin cotton and recycled fibers was obtained from knitted garment wastes collected in Addis Ababa, Ethiopia. HVI values of Middle Awash cotton are shown in table 1. 
Table 1: HVI values of virgin cotton

\begin{tabular}{|c|c|}
\hline Property & value \\
\hline Microniare $\mathrm{mg} /$ inch & 4.29 \\
\hline Maturity & 0.85 \\
\hline Length in $\mathrm{mm}$ & 27.12 \\
\hline Uniformity $\%$ & 78.7 \\
\hline Short fiber index & 8.0 \\
\hline Strength cN/tex & 27.8 \\
\hline Elongation & 8.0 \\
\hline (2) & \\
\hline
\end{tabular}

Figure 1: Processing of obtaining reclaimed fiber

Using specially designed carding machines in Etur textile PLC, which are much complicated and designed for recycled fibers, reclaimed fibers further opened, blended and parallelized to give slivers to the Openend opening machine to re spin the reclaimed fibers in to newer yarn. Ne 0.12 slivers were produced after two draw frame passages. In OE-rotor yarn production, rotor and opening roller revolutions were 9500 and $8600 \mathrm{rpm}$, respectively. The essential parameters under physical, structural and mechanical properties of produced yarn were measured by using Uster tester 4 SX, Uster Zweigle Hairiness Tester 5, Uster Tensorapid 3 and Lawson Hemphill CTT. After analyzing the properties of the OE rotor yarn produced by blending 100\% virgin cotton with recycled fibers. Different hand loom fabrics with $1 / 3$ twill and basic plain fabrics were produced. Since the recycled yarns have rough texture compared to yarns from virgin fibers it is difficult to make them warp during weaving process. So, the fabric is designed to have used recycled yarns as weft while $58 \mathrm{Ne}$ viscose cotton blend yarns used in the warp. The warp yarns are sized using wheat flour which boils at 80-90 degree Celsius for about 1 hour before weaving process in order to enhance the strength and resist the fatigue between yarns for reducing frequent yarn breakage.

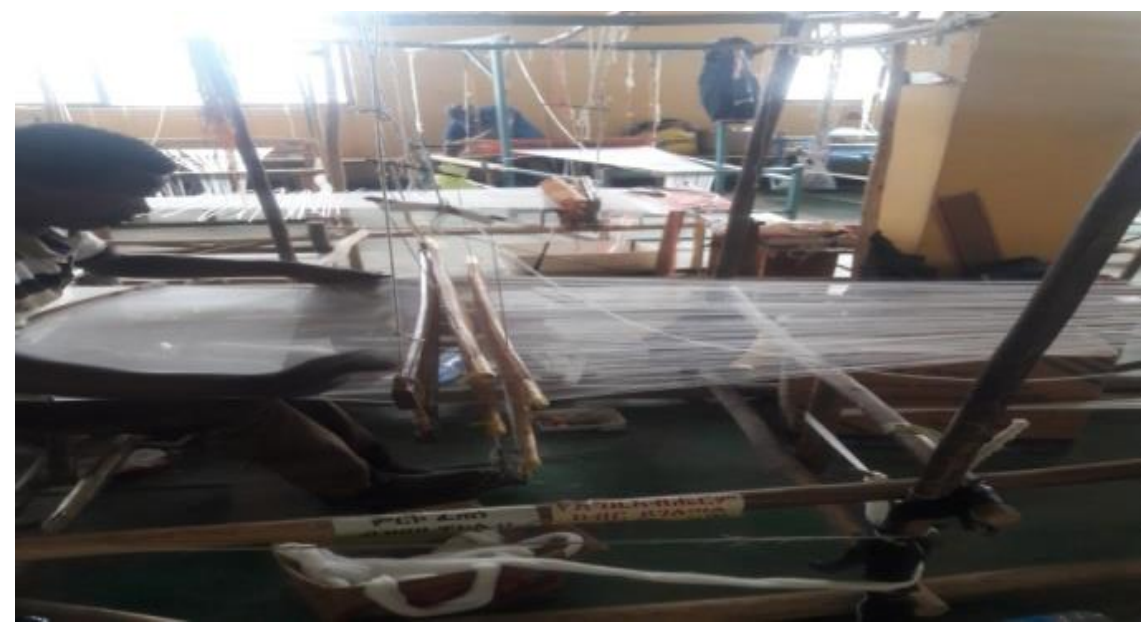

Figure 2: Hand loom weaving process 
A Comparative Study on Physical and Comfort Properties of Yarns and Hand-woven Fabrics Produced from Virgin and Recycled Fibers

The essential parameters under physical, structural and mechanical properties of produced yarn were measured by using Uster tester 4 SX, Uster Zweigle Hairiness Tester 5, Uster Tensorapid 3 and Lawson Hemphill CTT. After analyzing the properties of the OE rotor yarn produced by blending $100 \%$ virgin cotton with recycled fibers. Different hand loom $1 / 3$ twill and plain fabrics were produced using the yarns from $100 \%$ virgin cotton with recycled fibers, for the warp yarn during the warping process, the warp yarns are treated with tef starch in order to protect from the tension and friction of weaving operation. The starch solution is prepared by hand full of tef powder is added in $10 \mathrm{~L}$ of water boiled at $\left(80-90^{\circ} \mathrm{C}\right)$. Yarns are immersed in the solution for one hour. Then the moisture is pressed out from the threads and laid out to dry in the sun. And then the warps are tied in the shape of a ball. The effect of this yarn on the hand-woven fabric properties like Air-permeability, abrasion resistance, GSM, tearing, drape and pilling were evaluated.

\subsection{Abrasion and Pilling Test}

Ghosh \& Mal [14] described abrasion resistance of textile fabric is the ability to withstand loss of appearance, surface and utility due to destructive action of surface abrasion. The test is measured on Martindale abrasion tester by subjecting the specimen to abrasive action. The samples are rubbed against the same fabric at defined force. After completion of defined number of cycles, the degree of fuzziness and wear of the specimen are assessed. Also, it can be assessed by the number of cycles of the surface abrader required to rupture a yarn. By using SDL ATLAS M 235 Martindale Abrasion and Pilling Tester, after 5000 cycles the weight loss in mg. For pilling tendency test ISO 12945:2. Method is used. In this method the test specimens were determined by comparing with standard photographs. "5" rating means there is no visible change on the fabric surface after the test has been conducted.

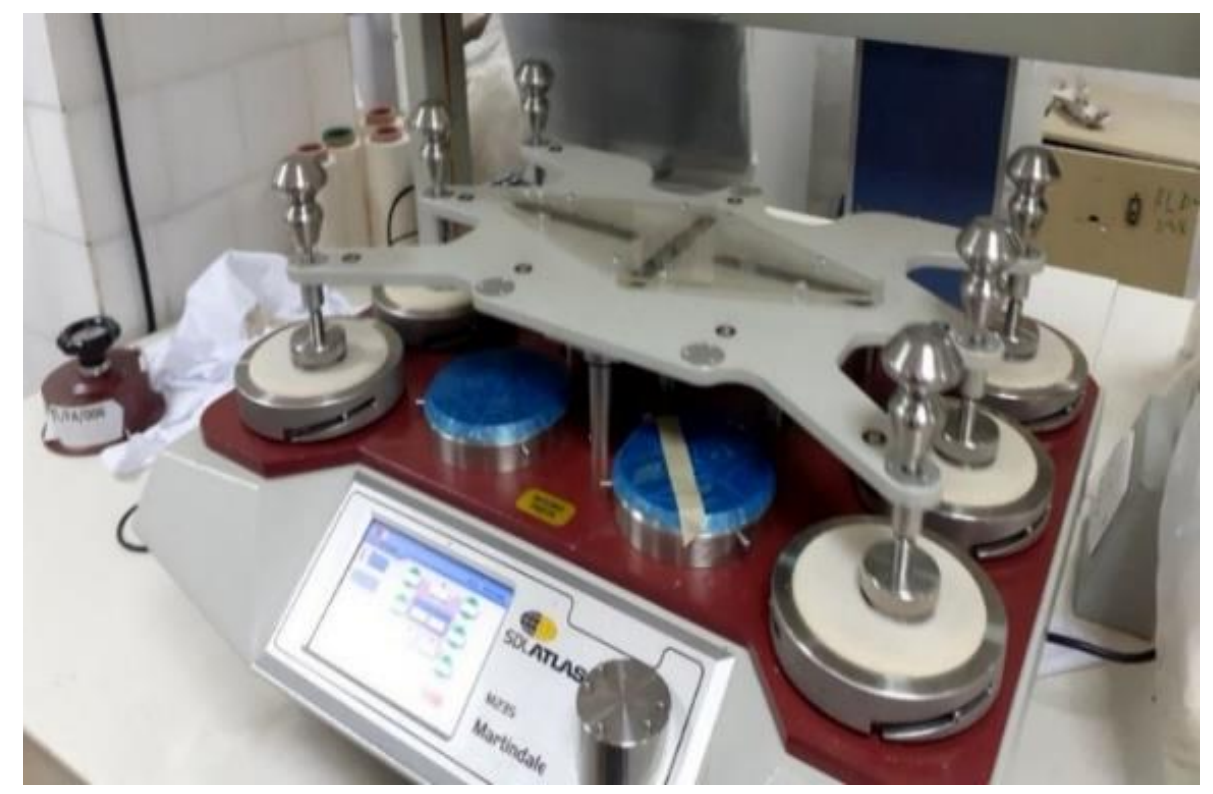

Figure 3: Abrasion resistance tester

\subsection{Air Permeability}

The amount of airflow passing through perpendicularly to a known area of fabric is adjusted to obtain a suggested air pressure differential between the two fabric surfaces and it's normally articulated in terms of $\mathrm{cm}^{3} / \mathrm{cm}^{2}$.s calculated at working conditions. From the amount of airflow, the air resistance of the nonwovens is resolute in accordance with the ISO 9237:1995Test Method. The necessity for determining the insulation properties of the fibrous media for forecasting the airflow resistivity was studied by and the measurements was carried out by using $20 \mathrm{~cm} 2$ circular fabric with 100 Pa pressure difference for 1 second and the results was expressed in $\mathrm{cm}^{3} / \mathrm{cm}^{2}$.s by taken the average of four different measurement. 

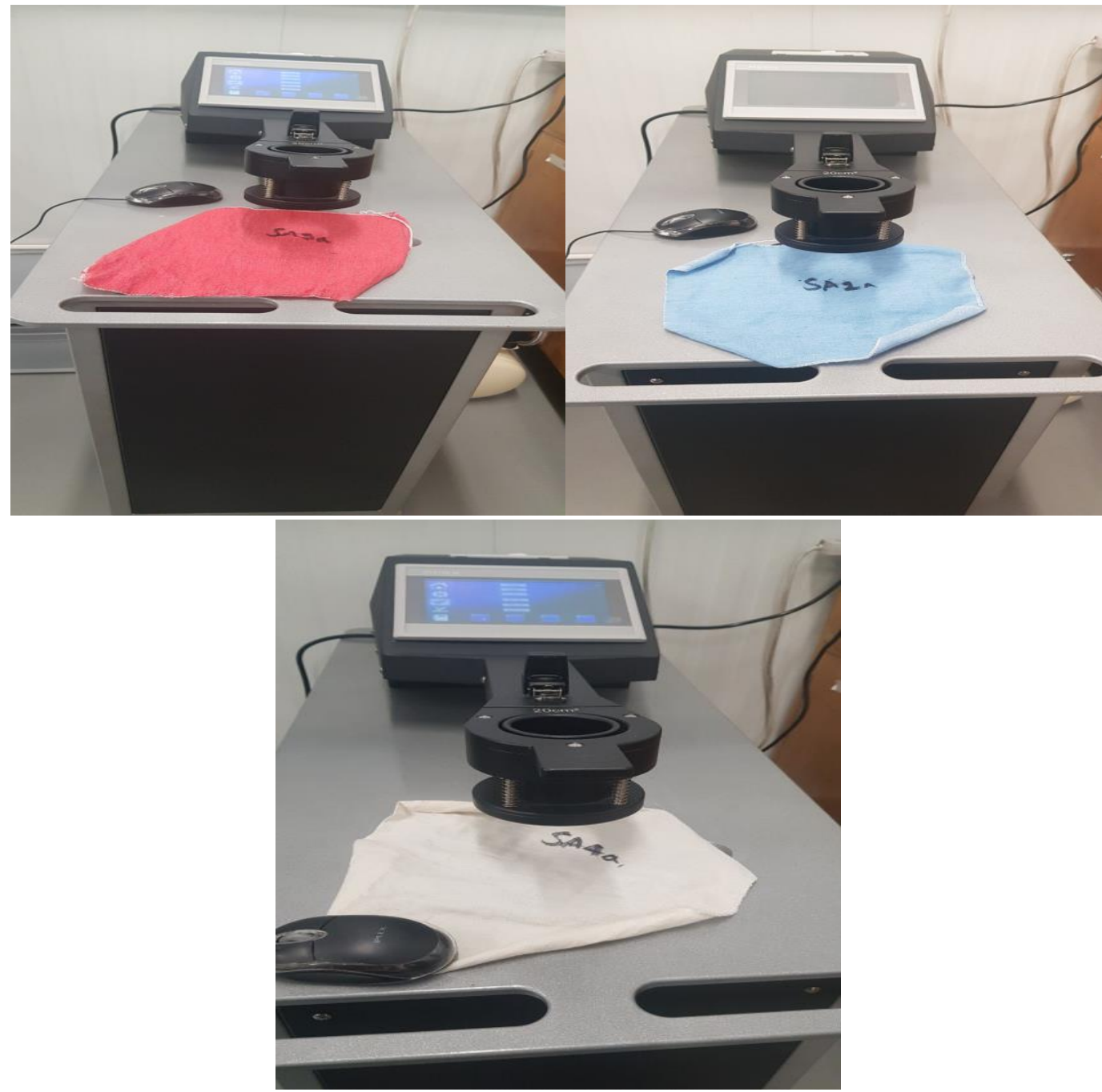

Figure 4: Air- permeability test

\subsection{Tearing test}

A textile would be regarded as inferior product if it tears easily. When a fabric is snagged through a rough object it generates a small puncture that can be converted into long rip by a small extra amount of force. ASTM used to determine the tearing force of woven fabrics. Hence, the propagation of tear is usually catastrophic. So, it defines that the tearing strength of a fabric is the force required to propagate an existing tear. The force is measured by the work done in tearing the fabric through a sample distance. Usually, Elmendorf tearing strength tester is used to find tearing strength of a fabric. This device consists of two clamps that is alignment with one fixed and another moving clamp with a pendulum which is raised at starting position at maximum potential energy. The fabric specimen is mounted in the clamps and an existing tear is created in the specimen between the clamps by cutting a small slit with a knife. The swinging pendulum is released from its higher height and the specimen is torn completely as the moving clamp in the pendulum moves away from the fixed clamp then, the tear force is calculated by reading the scale on the device and pendulum capacity. 


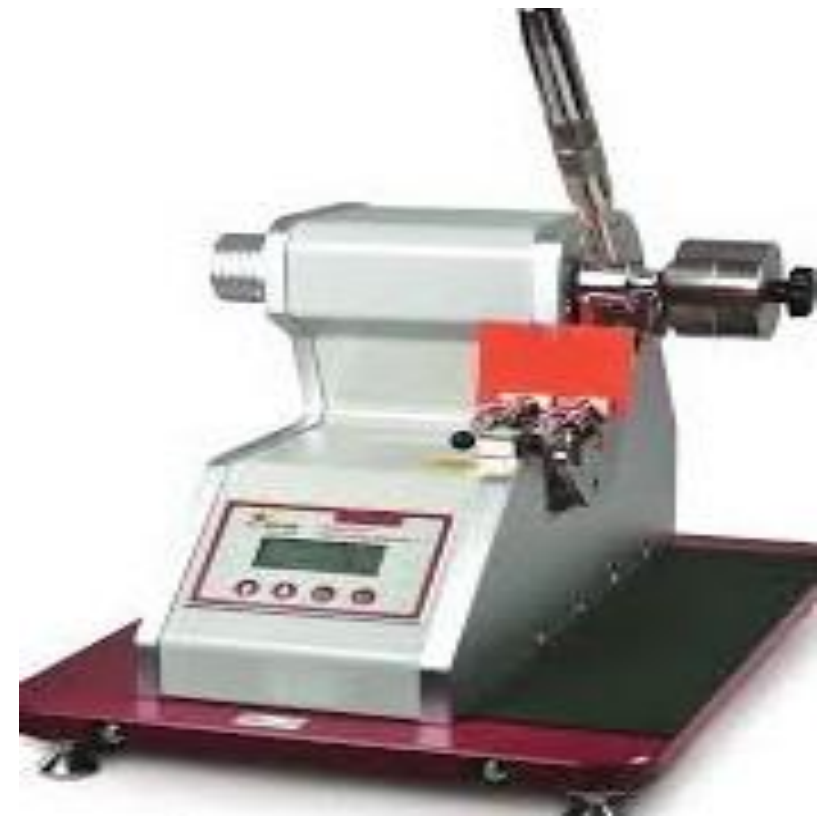

Figure 5: Elmendorf tearing strength tester

\subsection{Drapability test}

Fabric drape is the ability of the fabric to assume graceful appearance in use. The concept of bending length provides an approach for drape testing and evaluation in apparel products. Its only limitation is that it involves two-dimensional deformation where as drape is often a three-dimensional deformation. The threedimensional approach to evaluate fabric Drapability has found expression on development of an instrument called the drape meter for objective measurement of drape of fabrics.

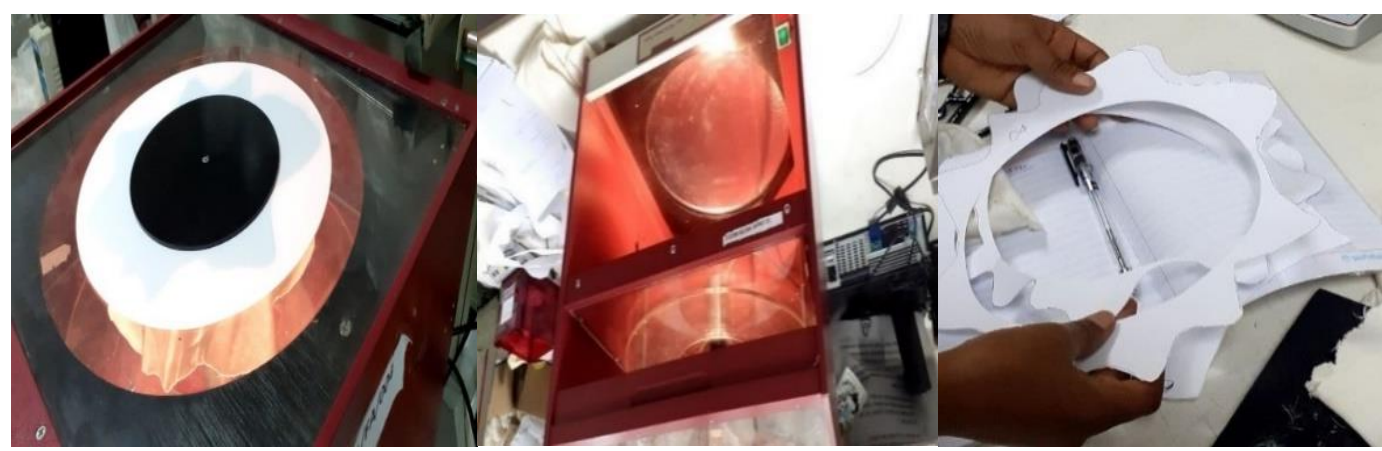

Figure 6: Drape test

A drape coefficient is described the degree of fabric deformation which is defined as percentage of draped fabric over initial flat state and can be achieved by vertical projection of the fabric. This means the high drape coefficient indicate a low Drapability of the fabric. In this instrument the coefficient of drape is calculated by tracing a shadow of drape fabric on the paper the instrument is lighted by a halogen light source, a cutting template and role of ammonia paper for tracing are supplied along with the instruments. To measure and calculate the drape coefficient of the fabric with BSI-BS 5058 testing method, by tracking the shadow on the paper. The samples are prepared with a circular disc diameter $36 \mathrm{~cm}$ and the paper ring for the capturing the shadow of the draped fabric. Weight of the paper is $4.52 \mathrm{gm}$

\subsection{Fabric GSM test}

For calculating gram per square meter (weight of fabric per square meter) of the ASTM D3776standard is used. The specimen is prepared by cutting the fabric with Gsm cutter by applying force. Circular samples 
Awgichew et al., J. Mod. Mater.; Vol. 8, Issue 1, pp: 52-66, 2021

which are $100 \mathrm{~cm} 2$ area from different parts of the fabric prepared. The samples are placed on the digital weight balance. Calculating the average of the test results multiplied by 100 to get the Gsm of the fabric.

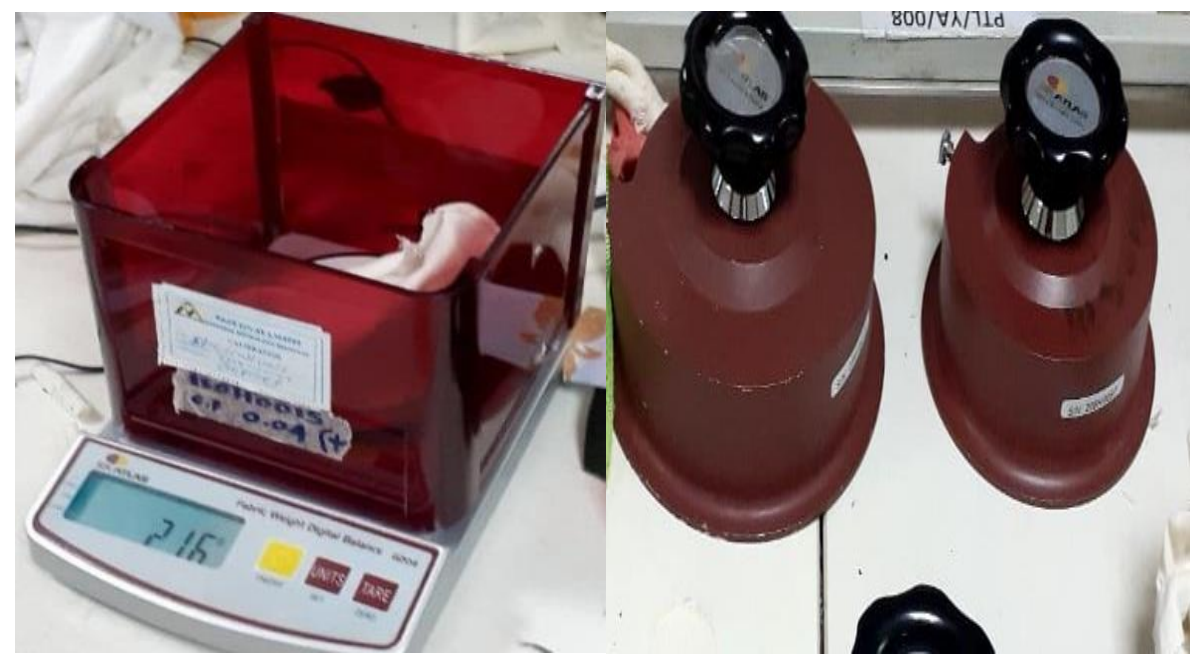

Figure 7: GSM cutter and digital balance

\section{Results and Discussion}

Evaluation of yarn properties for a better understanding of how usage of recycled fiber affects quality of OE-rotor spun yarns, properties such as unevenness, imperfections, hairiness, breaking force, breaking elongation were analysed statistically using ANOVA and confidence interval graphs at $95 \%$ confidence level. The unevenness of recycled yarn increased because of recycled fiber content in the yarns they become out of the fiber cross section as their difference in length with the virgin fiber stands this tends to create cross sectional difference in the yarn throughout its length.

Table 2: Average Yarn Test Results for Samples

\begin{tabular}{|c|c|c|c|c|c|c|c|}
\hline Samples & Unevenness & Hairiness & Strength & Elongation & \multicolumn{3}{|c|}{ Imperfection } \\
& & Index & Cn/Tex & $\%$ & $\begin{array}{c}50 \% \\
+50 \% \\
\text { thin } \\
\text { place }\end{array}$ & $\begin{array}{c}\text { thick } \\
\text { place }\end{array}$ & +280 neps \\
\hline$(100 \% \mathrm{VC})$ & 9.256 & 5.313 & 14.96 & 4.803 & 3.333 & 35.42 & 27.866 \\
\hline$(75 \%-25 \% \mathrm{VC}-\mathrm{R})$ & 10.813 & 5.18 & 10.303 & 6.313 & 9.33 & 40.366 & 32.33 \\
\hline$(50 \%-50 \% \mathrm{VC}-\mathrm{R})$ & 10.533 & 5.44 & 12.126 & 6.386 & 3.666 & 41.8 & 36.66 \\
\hline$(25 \%-75 \% \mathrm{VC}-\mathrm{R})$ & 10.923 & 5.15 & 13.066 & 5.923 & 4.66 & 30 & 28 \\
\hline
\end{tabular}

\subsection{Yarn properties}

Table 3: ANOVA Results for Unevenness Values

$\begin{array}{llrc}\text { R-Square } & \text { Coeff Var } & \text { Root MSE } & \text { uneveness Mean } \\ 0.519596 & 7.903444 & 0.826700 & 10.46000\end{array}$




\subsubsection{Uneveness and hairiness}

Unevenness and proportion of recycled fibers show parallel increase due to the increasing amount of short fibre in the yarn. However, there is no statistically significant difference amongst the blended yarns. Table 3 provides the ANOVA results and table 4 shows the pair wise comparisons of the yarn types. In rotor spinning, fine trash and dust content can accumulate in the grooves leading to more end breakages and hence an increase on the level of yarn irregularity. This results into increased fiber agglomeration at the collection point which causes a reduction in the overall yarn uniformity. As it is indicated in Table 3 , recycled fibers usage has no statistically significant difference on yarn unevenness $(\mathrm{p}=0.0743)$. Moreover, according to the results from table 4 the pair wise analysis of the yarn samples except for $(100 \% \mathrm{VC}$ with 25-75 VC-R,) there is no statistically significant difference between other samples at $(p<0.05)$. The appearance result of sample OE yarns made from 100\% virgin cotton and recycled fiber blends tested. It illustrates that sample appearance values area unit hyperbolic till the recycled fiber proportion is equal with The Virgin cotton except for mix quantitative relation of (25\% virgin cotton $75 \%$ recycled fiber) it's reduced a little bit.

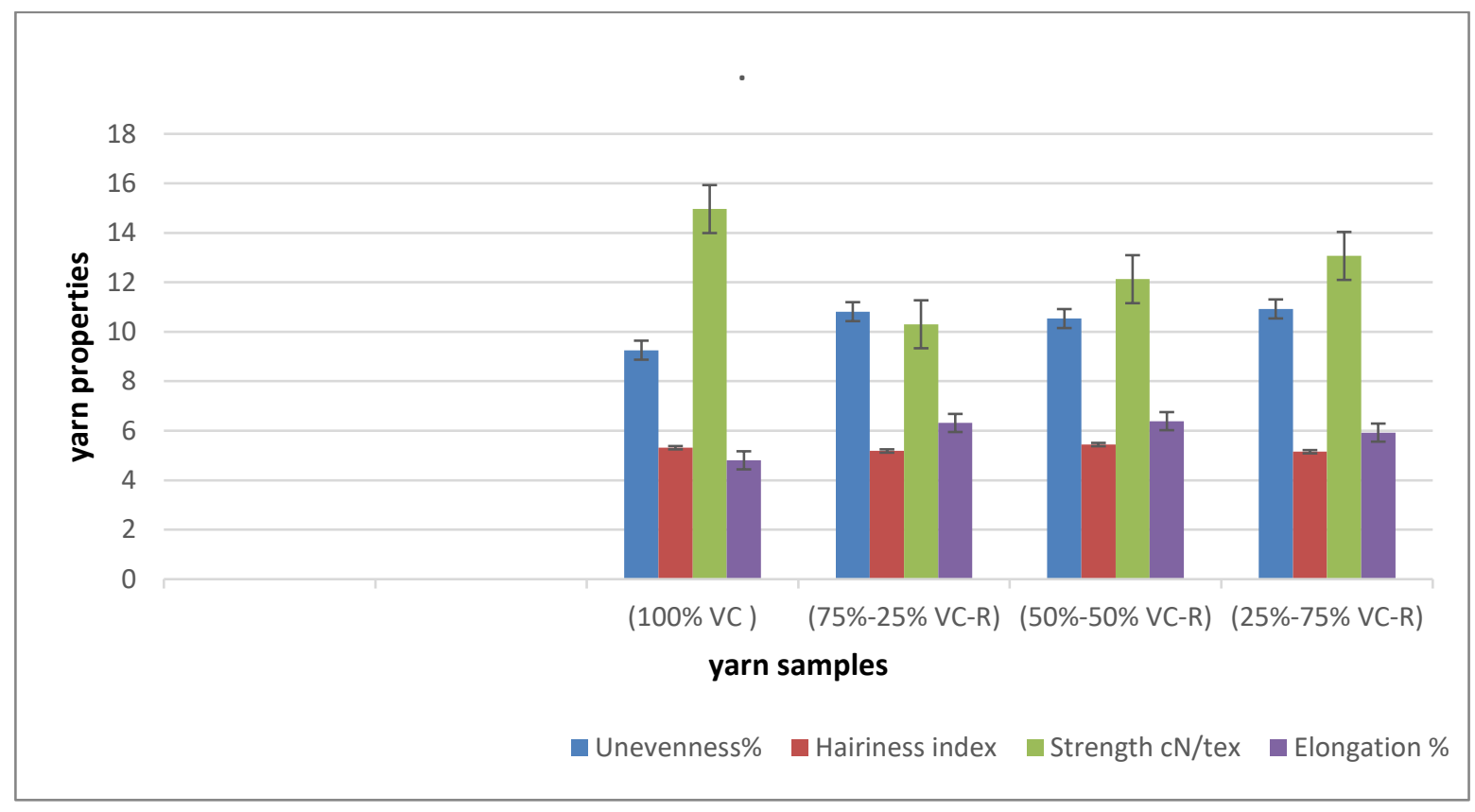

Figure 8: Properties of produced yarns

\subsubsection{Breaking force and elongation}

Figure 8 shows breaking force and breaking elongation values. 100\% VC fiber yarns have the highest breaking force with the lowest elongation values. Higher length uniformity ratio values hinder fiber slippage during spinning which improves on the yarn elongation. Short fibers have been found to work well with rotor spinning machines due to reduction on poor fiber orientation and the formation of wrapper fibers resulting from longer lengths during spinning. The basic objectives of textile testing are the checking of raw materials, monitoring of production, assessment of final product, investigation of faulty materials, product development and research. The number of fibres that extend to a distance from the baseline of the clamp is estimated by means of the intensity of light that passes through the beard at that position. Fibre bundle strength is usually measured for cotton. Conventionally, fibre bundle strength is measured using a Stelometer that works with the constant rate of loading principle. Usually, fabrics shrink during garment manufacturing and washing due to relaxation of the fibres/yarns, swelling of fibres and felting. A snag is loop of fibres that is being pulled from a fabric when it is in contact with a sharp or rough object. The stained white fibre of the multi-fibre fabric is then compared with the corresponding fibre of untreated 
white multi-fibre fabric with reference to grey scale for colour staining [14]. However, excess amounts of short fibers are also undesirable since it can lead to increased ends-down at the opening stage and hence a deterioration in yarn properties of strength, elongation and uniformity. unlike ring spinning, increasing count reduces on the number of fibers in the yarn cross section reaching the spinning point during yarn formation. This affects the spinning stability causing yarn breakages and poor fiber orientation which ultimately affects yarn strength The effect of blending proportion (virgin cotton fiber and recycled fiber) is clearly shown in the figure as the proportion of the recycled fiber increases the strength and elongation of the yarn is also increases. It is related with increasing number of synthetic fibers that have strong breaking strength and elongation values.

\subsubsection{Imperfections}

The effects of recycled fiber proportion on imperfections are illustrated in figure 9. the formation of short fibers which may end up being twisted into the yarn and hence forming thick places. thus, advices that in order to minimize on the level of irregularity and imperfections, it's necessary to ensure proper fiber individualization at the carding stage, proper fiber drafting system especially with short fibers and minimization on the level of short fiber content. As it is shown that $100 \%$ virgin cotton yarn exhibits lower number of thin places while (75-25\% VC-R) has higher amount of thin place. For the proportions of (75$25)$ and (50-50) neps percent is higher whereas (25-75) ratio shows equivalent neps percent with $100 \%$ virgin cotton yarns. Neps in rotor spun yarns are a representation of high number of wrapper fibers and they result from increased rotor speeds, small rotor diameter, reduced rotor groove, increased yarn count, fiber length and fiber fineness as stated by Lawrence, 1992. Except for the number of thin places of blend ratio (75\% virgin cotton and $25 \%$ recycled fiber) there is no significance difference between all the tests. The result of ratio ( $75 \%$ virgin cotton and $25 \%$ recycled fiber) is related to rotor speed not blend proportion.

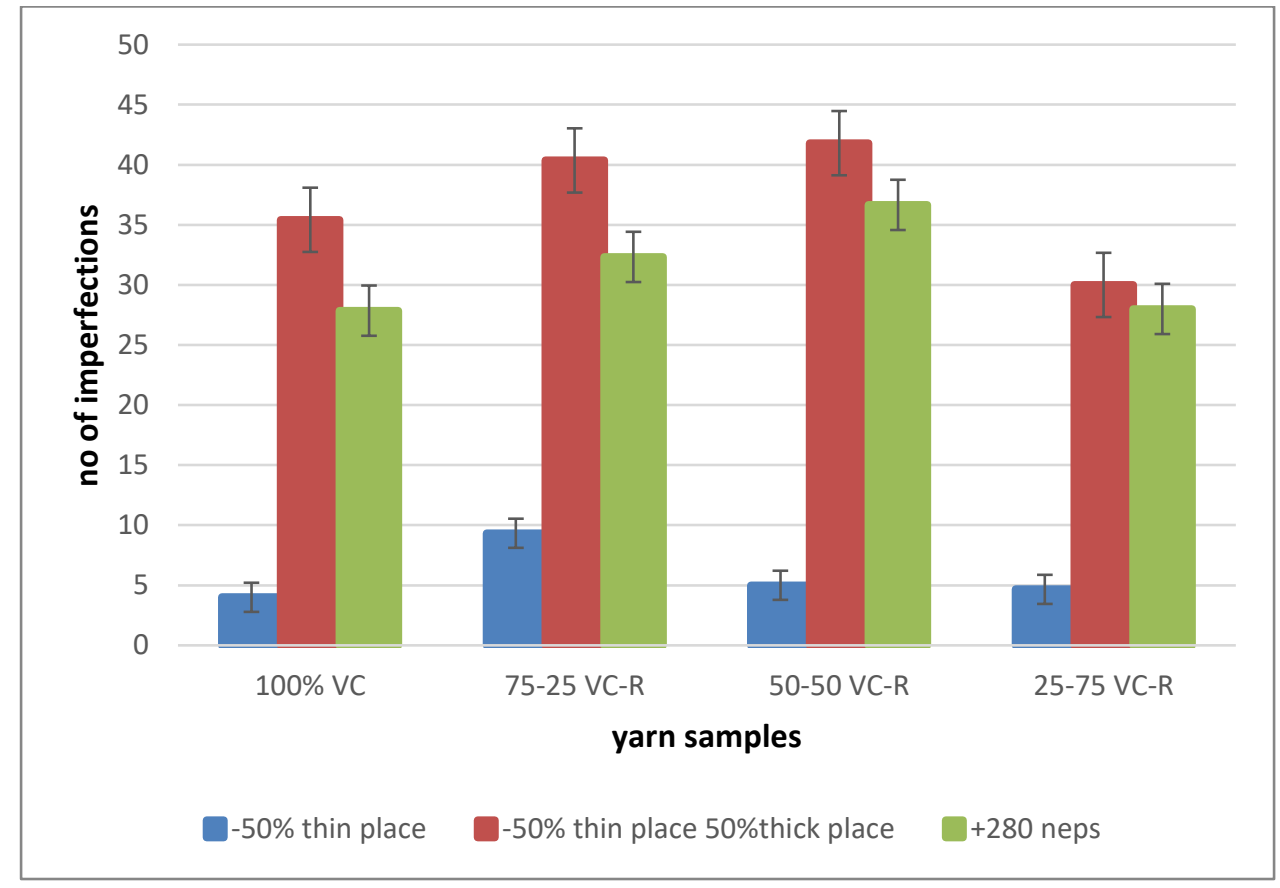

Figure 9: Imperfection of produced yarns

\subsection{Fabric evaluation}

\subsubsection{Air permeability}

Figure shows air permeability values for the produced fabrics. It is observed that the air permeability of hand-woven fabrics decreases by increasing proportion of recycled fiber usage with no significance difference shown between samples except plain weave $75 \%$ virgin cotton $-25 \%$ recycled fibers. The Anova 
A Comparative Study on Physical and Comfort Properties of Yarns and Hand-woven Fabrics Produced from Virgin and Recycled Fibers

analysis of average results between the samples exhibits value of $(\mathrm{p}=0.253089)$ which is no statistically significant difference at 95\% confidence level. On the other hand, twill (TW) weave hand loom fabric made from virgin cotton and recycled fiber blends has better resistance to air flow while plain (PL) weaves are lower air flow resistance through the fabric surface. This is because of twill hand loom fabric weave are denser while plain hand loom fabrics are porous. Similar findings given by Kilic et el. [15]

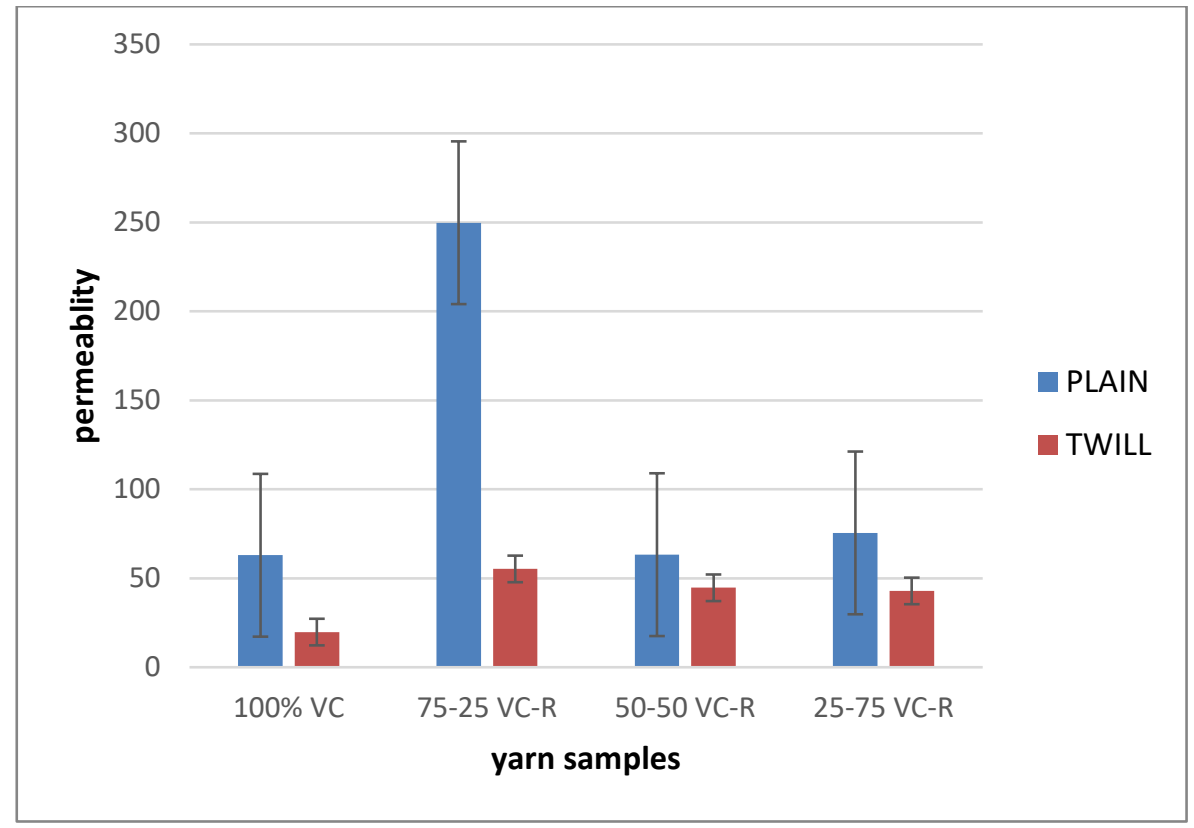

Figure 10: Air permeability $\mathrm{cm}^{3} / \mathrm{cm}^{2} . s$

Table 4: ANOVA of air permeability

\begin{tabular}{|l|c|c|c|c|c|c|}
\hline Source of Variation & SS & $d f$ & MS & $F$ & P-value & F crit \\
\hline Between Groups & 32374.06 & 5 & 6474.812 & 1.454719 & 0.253089 & 2.772853 \\
\hline Within Groups & 80116.25 & 18 & 4450.903 & & & \\
\hline & & & & & & \\
\hline Total & 112490.3 & 23 & & & & \\
\hline
\end{tabular}

\subsubsection{Tearing strength}

The ability of the fabric to resist the shearing force, when fabric has greater tearing force, it is safer. During the analysis of the samples show statistically almost similar characteristics whereas the blend proportion of $25 \%$ virgin cotton and $75 \%$ recycled fibers show a lower tearing strength between samples. From weave type of produced fabrics plain weave samples have a little higher than twill weaves. The warp way tearing is better than the weft way tearing this is because of the warp yarns are treated with starch from tef powder during warp preparation. During the Anova analysis there is no significant difference between them with value of $(p=0.667806)$ this is high number of short fibers aligned with small amount of virgin fibers which cause some weak points at the yarn cross section that can cause a weak spot on the produced handloom fabric too, when sudden impact force is applied the it easily gets a path to tear the fabric. 
Awgichew et al., J. Mod. Mater.; Vol. 8, Issue 1, pp: 52-66, 2021

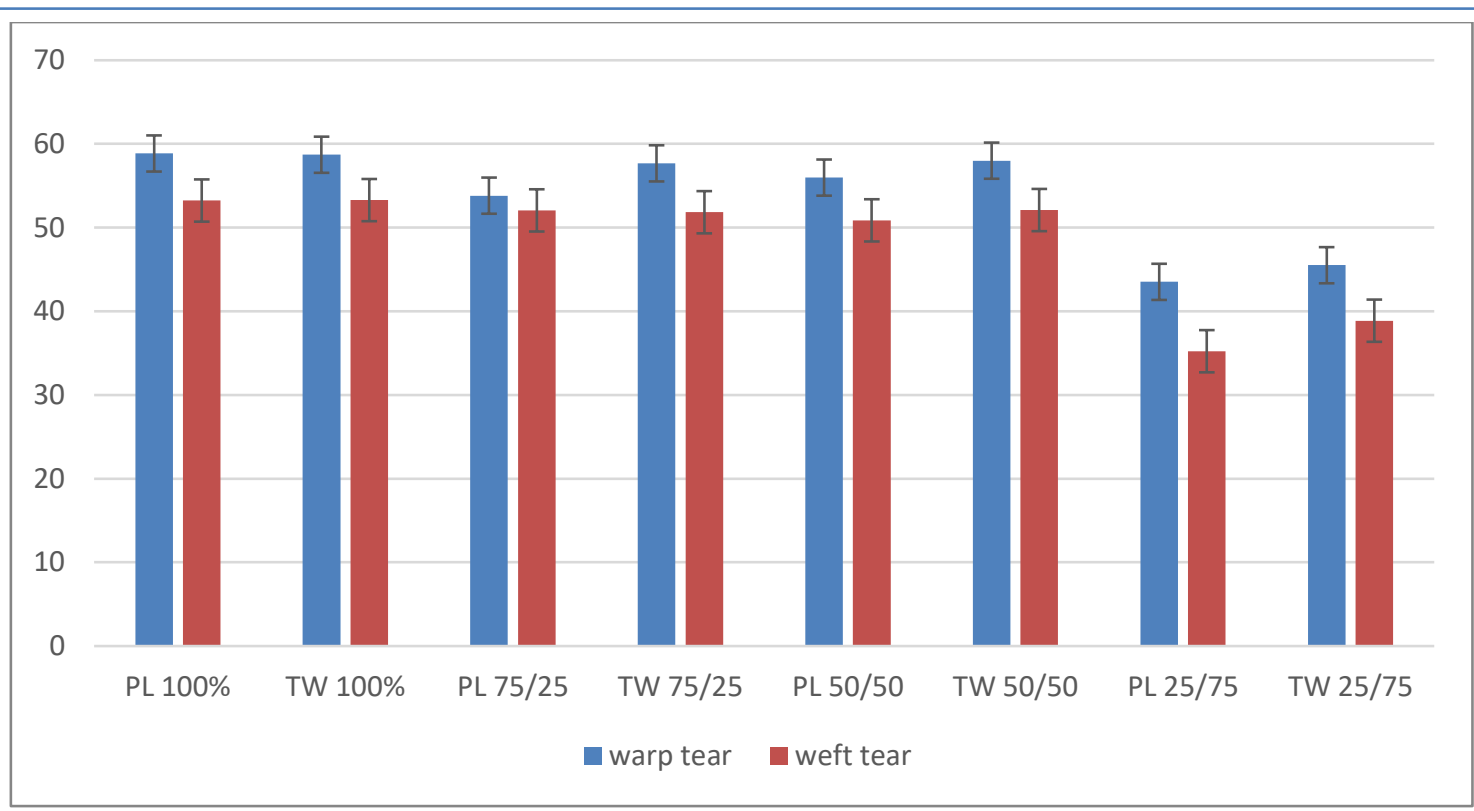

Figure 11: Tearing strength of the produced fabric samples

Table 5: ANOVA of tearing

\begin{tabular}{|l|r|r|r|r|r|c|}
\hline Source of Variation & \multicolumn{1}{|c|}{ SS } & $d f$ & MS & \multicolumn{1}{c|}{$F$} & P-value & F crit \\
\hline Between Groups & 263.088 & 7 & 37.584 & 0.705131 & 0.667806 & 2.422629 \\
\hline Within Groups & 1279.218 & 24 & 53.30074 & & & \\
\hline Total & 1542.306 & 31 & & & & \\
\hline
\end{tabular}

\subsubsection{Drapability}

Figure 12 shows the drapablity of the hand-woven fabrics made from recycled fibers blended with virgin cotton. As the recycled fiber proportion is increased the drapablity is decreased. Plain fabrics made from recycled blended yarns have better drapablity whereas the twill have a little less drapablity as their drape coefficient is higher good average drapablity coefficient with $37 \%$ minimum to $61.5 \%$ maximum which is suitable for house hold textiles and clothing. With the Anova analysis between the produced fabric samples the value of $(p=0.974764)$ shows no significance difference at $\mathrm{p}<0.05$

Table 6: ANOVA of drapability test

\begin{tabular}{|l|r|c|c|c|c|c|}
\hline Source of Variation & SS & $d f$ & MS & $F$ & P-value & F crit \\
\hline Between Groups & 18.190225 & 3 & 6.063408 & 0.070214 & 0.974764 & 3.490295 \\
\hline Within Groups & 1036.27415 & 12 & 86.35618 & & & \\
\hline Total & 1054.464375 & 15 & & & & \\
\hline
\end{tabular}

It shows the drapability of fabrics produced from recycled yarns blend are good and can be used for Draperies, cushion covers, table cloths and also shopping bags. Similar findings were obtained by Alexander et al. [16] 


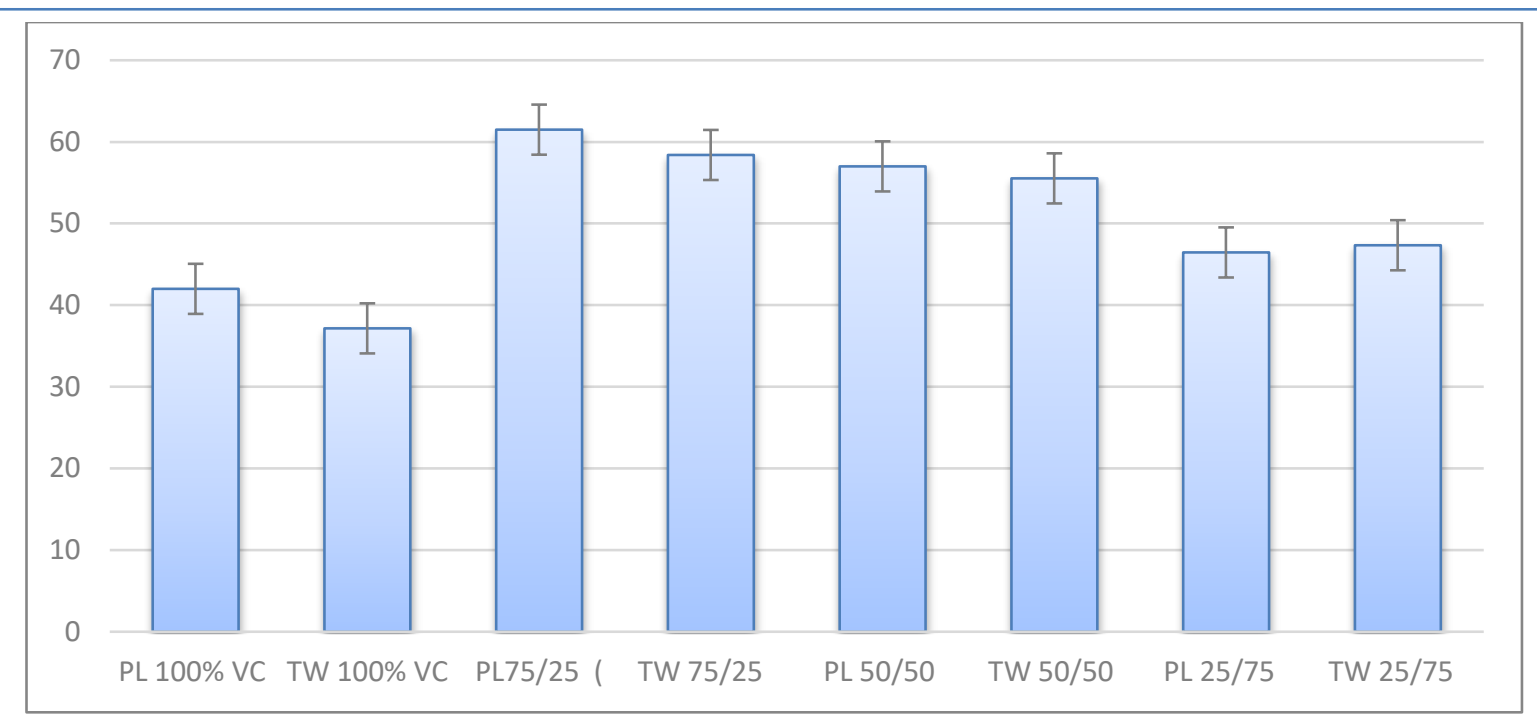

Figure 12: Drapability of the produced fabrics

\subsubsection{GSM (weight per $\mathrm{cm}^{2}$ )}

The weight per centimeter square (Gsm) of the produced hand-woven fabrics shown the hand-woven fabrics. As the proportion of reclaimed fibers increased the Gsm of the fabrics are increased. Twill weaves are heavier and denser than plain weave of the same yarns from reclaimed blended fibers. From all samples produced fabrics made from recycled fibers blended with virgin cotton twill 50/50 VC-R register the highest Gsm values where as plain 100\% virgin cotton fabric have lowest average Gsm this is due to that the short fibers increased the uneven mass that have entangled mass of fibers and thick places increased.

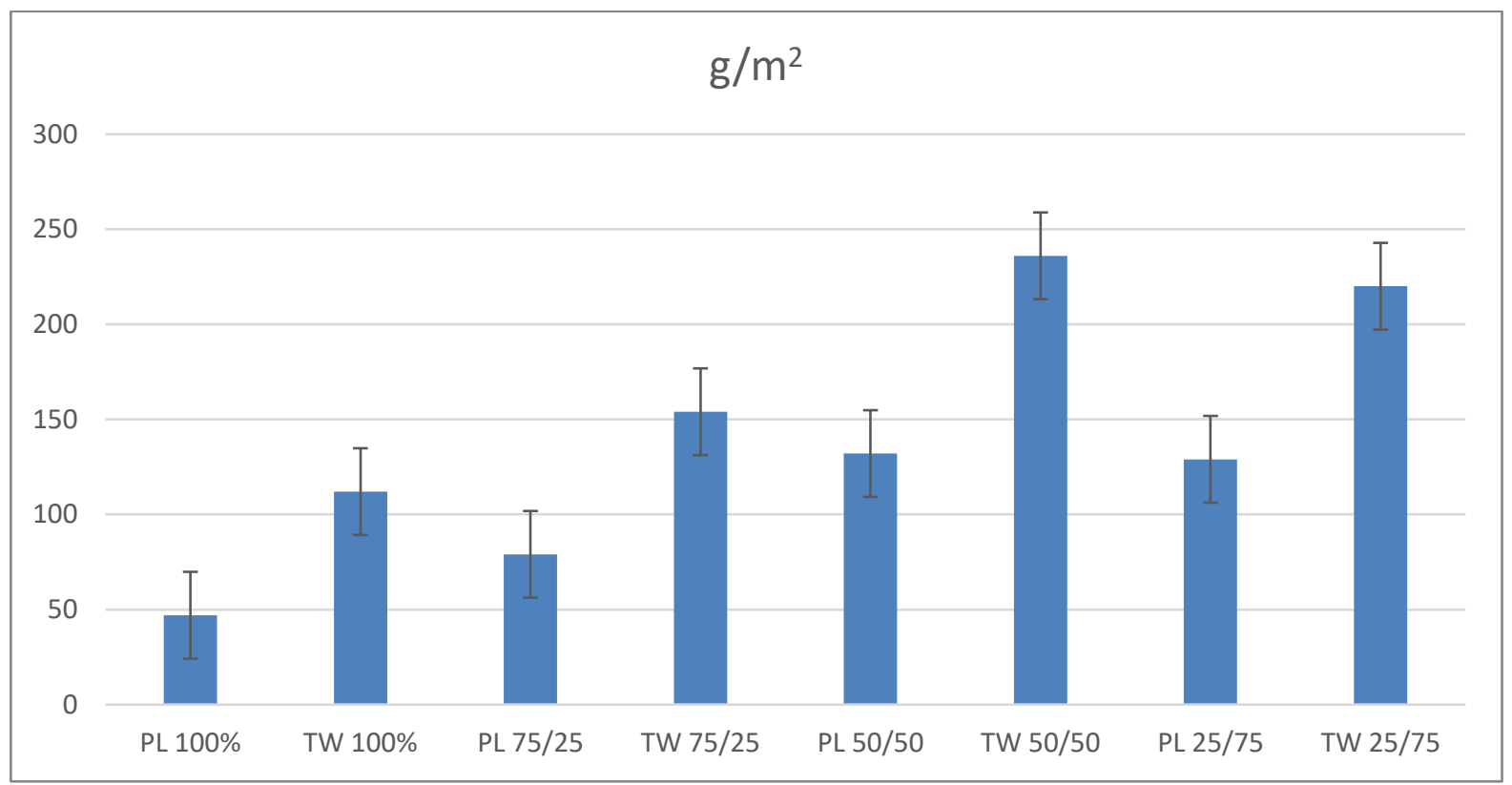

Figure 13: GSM of produced fabrics

Table 7: ANOVA of GSM test

\begin{tabular}{|l|c|c|c|c|c|c|}
\hline Source of Variation & SS & $d f$ & MS & $F$ & P-value & F crit \\
\hline Between Groups & 14028.13 & 1 & 14028.13 & 5.57123 & 0.056258 & 5.987378 \\
\hline Within Groups & 15107.75 & 6 & 2517.958 & & & \\
\hline Total & 29135.88 & 7 & & & & \\
\hline
\end{tabular}


Awgichew et al., J. Mod. Mater.; Vol. 8, Issue 1, pp: 52-66, 2021

The ANOVA analysis between the samples at $\mathrm{p}<0.05$ value have no statistically significance difference with $(\mathrm{p}=0.056258)$. Gsm categorized on three different regions. Gsm between 30-150 light weight fabrics, 150350 medium weight and above 350 heavy weights, the results obtained from the experiment are described below in figure 26. based on the results the hand-woven fabric produced is light weight fabric category. From results obtained the sample fabrics produced from reclaimed fibers of garment wastes are suitable for home furnishing application like table covers, pillow cases, curtains and draperies.

\subsubsection{Pilling}

The short fiber contents have direct effect on the pilling tendency of produced fabrics with the different design. Pilling tendency of the produced fabrics increased with the increasing proportion of recycled fibers. Plain weave samples have better pilling resistance than twill samples since twill fabrics are denser than plain weave the abrader gets larger surface areas of yarns in twill. The average values for pilling of samples are with the range of good to moderate with minimum 8.66 and maximum 36.66 values.

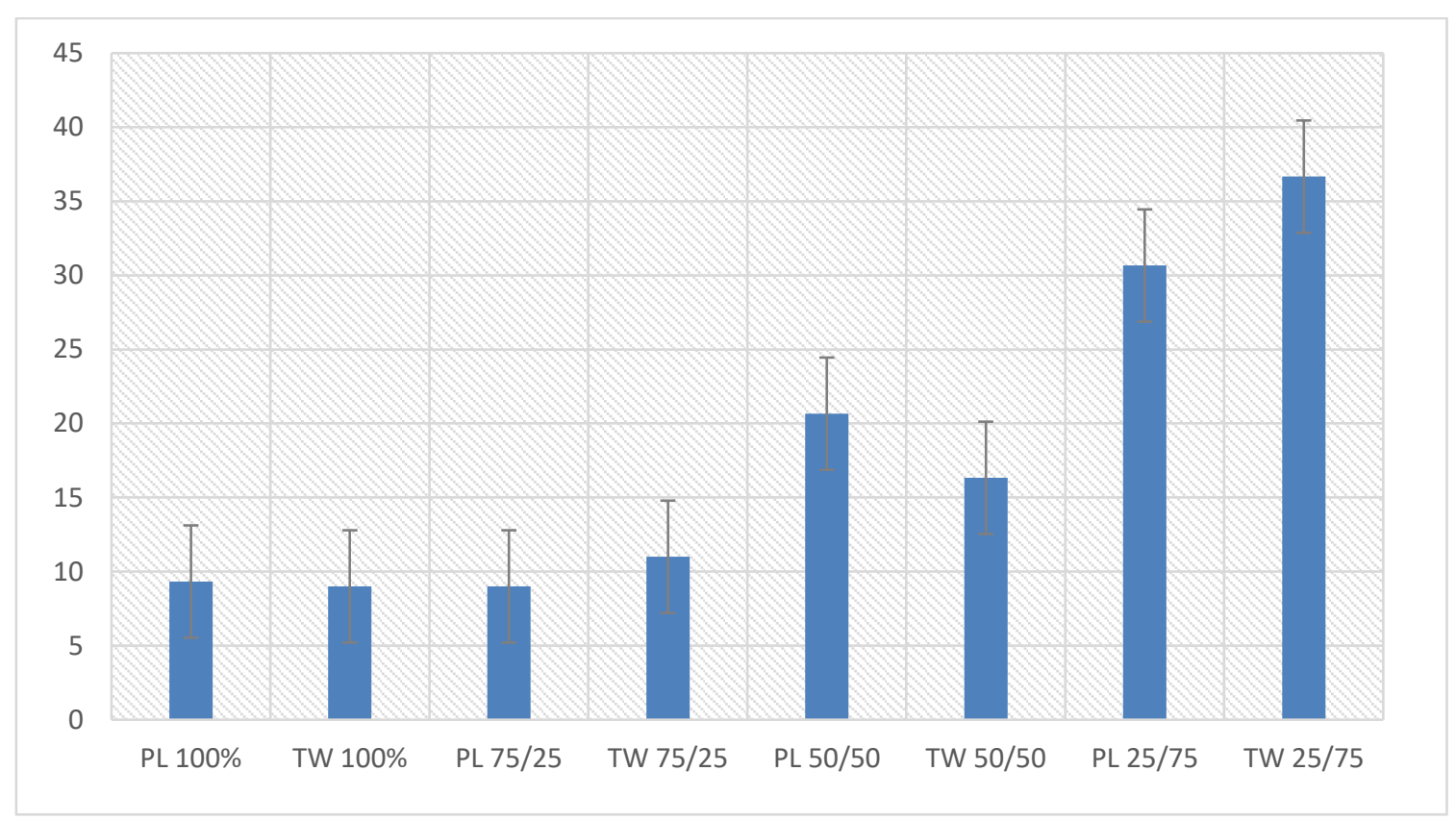

Figure 14: Pilling of the produced fabrics

Table 8: ANOVA of pilling test

\begin{tabular}{|l|c|c|c|c|c|c|}
\hline Source of Variation & SS & $d f$ & $M S$ & $F$ & P-value & F crit \\
\hline Between Groups & 0.348613 & 1 & 0.348613 & 0.002654 & 0.960588 & 5.987378 \\
\hline Within Groups & 788.2034 & 6 & 131.3672 & & & \\
\hline Total & 788.552 & 7 & & & & \\
\hline
\end{tabular}

The analysis of ANOVA at $\mathrm{p}<0.05$ the samples show no statistically significance difference with $(p=0.960588)$ but as the ratio of recycled fiber is increased the pilling tendency is increased this is due to the short fibers tendency to create entangled mass on the surface of the fabric which pill out to increase the masses when subjected to abrader.

\subsubsection{Weight loss}

The hand loom fabrics made from the recycled blended fibers have shown weight loss properties that as the proportion of reclaimed fibers increased the weight loss of the fabrics under an abrasion force are 
A Comparative Study on Physical and Comfort Properties of Yarns and Hand-woven Fabrics Produced from Virgin and Recycled Fibers

increased. Beside these, plain fabrics made from the produced yarns have a better resistance to abrasion force than twill fabrics of the same yarn.

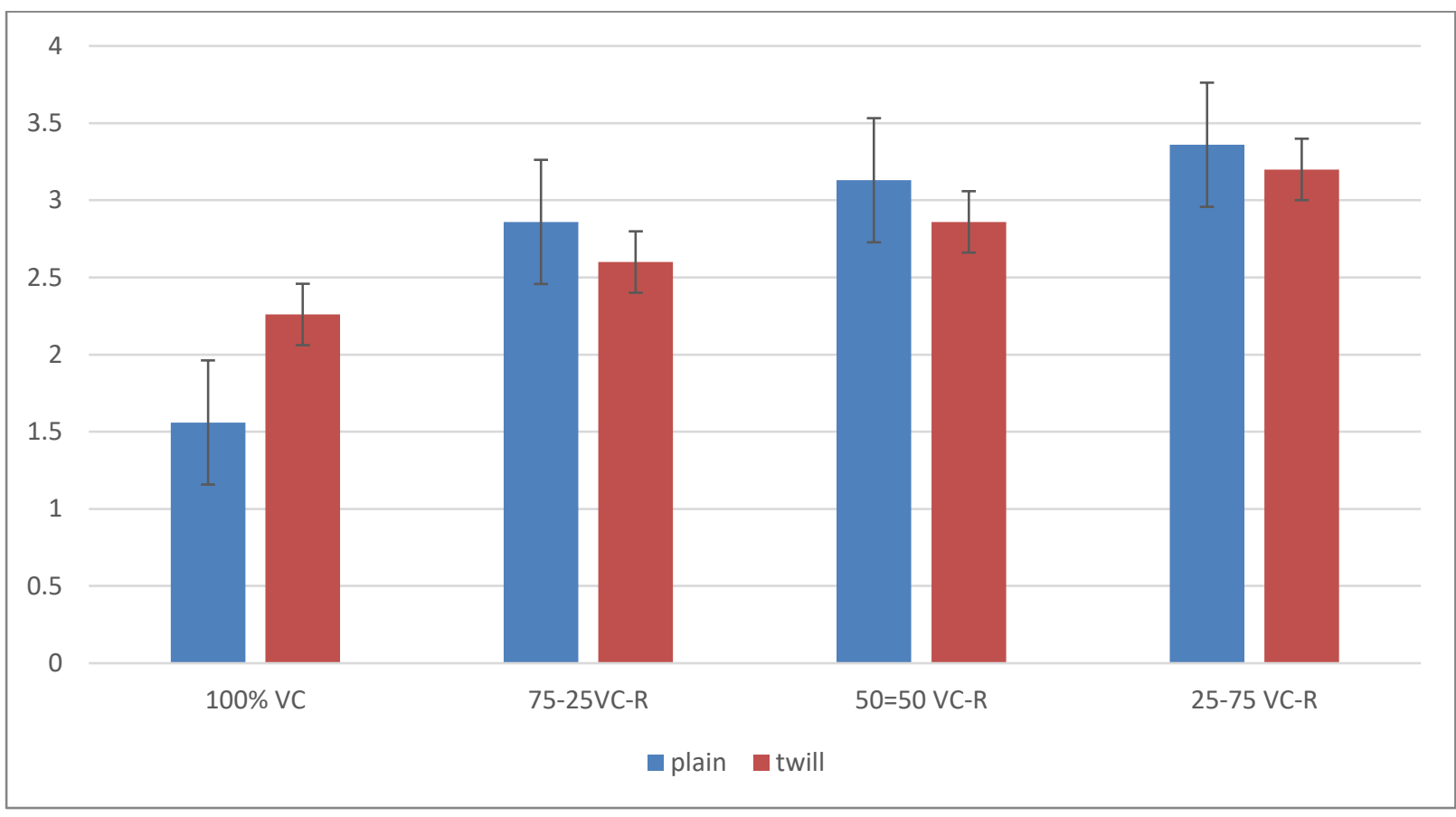

Figure 15: Weight loss \% of produced fabrics

A home furnishing fabric is subjected for many abrading forces during service so, it is one of the essential criteria of the fabric requirements Abrasion is the wearing a way of any part of a textile material by rubbing against another surface this determines the service time of the fabric for specific application. Based on the Anova analysis in $\mathrm{p}=0.05$ of the results obtained from the samples show that there is no significant difference between the test results with the value of $\mathrm{p}=0.995737$. but, as the proportion of reclaimed fibers are increased the weight loss of the fabric samples also increased. This is due to that as the short fibers increased the rotor yarn evenness decreases hence the short fibers wound on the yarn cross section with out twist this causes high amount of entangled masses which worn out easily by rubbing and abrading forces.

Table 9: ANOVA of Wight loss test

\begin{tabular}{|l|c|c|c|c|c|c|}
\hline \multicolumn{1}{|c|}{ Source of Variation } & SS & $d f$ & $M S$ & $F$ & P-value & F crit \\
\hline Between Groups & $1.25 \mathrm{E}-05$ & 1 & $1.25 \mathrm{E}-05$ & $3.1 \mathrm{E}-05$ & 0.995737 & 5.987378 \\
\hline Within Groups & 2.418275 & 6 & 0.403046 & & & \\
\hline Total & 2.418288 & 7 & & & & \\
\hline
\end{tabular}

\section{Conclusion}

For analyzing the effect of recycled fibers usage on the properties of yarns and hand loom fabrics OE-rotor yarns made of $100 \%$ virgin cotton blended with different proportions (25\%,50\% and $75 \%$ ) were produced. Yarns mechanical properties such as tensile strength, elongation, unevenness and yarn imperfections are measured and Fabric properties measured were tearing strength, pilling grade, Gsm, Drape, Airpermeability and weight loss. From the results of the data analysis of sample tests it can be concluded that using up to $75 \%$ recycled fibers is more economical, and environmentally friendly with no or, minimum difference in physical, structural and mechanical properties of yarns and fabrics produced. Based on the results of this study, yarns and fabrics produced from recycled fibers blended with virgin cotton are suitable for applications where the strength of yarns and fabric are less critical, but where unevenness, imperfections 
and handle properties required thus, hand loom fabrics Produced can suitably use for home furnishing applications like table cover, curtains, wall covers and pillow cases.

\section{Competing Interests}

The authors did not declare any know conflict of interest in this work.

\section{How to Cite this Article:}

D. Awgichew, S. Sakthivel, M. Gedlu, and M. Bogale, "A Comparative Study on Physical and Comfort Properties of Yarns and Hand-woven Fabrics Produced from Virgin and Recycled Fibers", J. Mod. Mater., vol. 8, no. 1, pp. 52-66, Dec. 2021. https://doi.org/10.21467/jmm.8.1.52-66

\section{References}

[1] D. Awgichew et al., "Experimental Study and Effect on Recycled Fibers Blended with Rotor/OE Yarns for the Production of Handloom Fabrics and Their Properties," Adv. Mater. Sci. Eng., vol. 2021, p. e4334632, Aug. 2021, doi: 10.1155/2021/4334632.

[2] B. Zamani, Towards understanding sustainable textile waste management: Environmental impacts and social indicators. Chalmers Tekniska Hogskola (Sweden), 2014.

[3] S. Rani and Z. Jamal, "Recycling of textiles waste for environmental protection," Int. J. Home Sci., vol. 4, no. 1, pp. 164-168, 2018.

[4] S. Kavitha and G. Manimekalai, "A study on waste disposal management in garment industry," Int. J. Text. Fash. Technol. IJTFT, vol. 4, no. 5, pp. 37-42, 2014.

[5] H. Mohamed Taher, A. Bechir, B. H. Mohamed, and S. Faouzi, "Influence of Spinning Parameters and Recovered Fibers from Cotton Waste on the Uniformity and Hairiness of Rotor Spun Yarn," J. Eng. Fibers Fabr., vol. 4, no. 3, p. 155892500900400, Sep. 2009, doi: 10.1177/155892500900400304.

[6] S. Adanur and J. Qi, "Property Analysis of Denim Fabrics Made on Air-jet Weaving Machine Part II: Effects of Tension on Fabric Properties," Text. Res. J., vol. 78, no. 1, pp. 10-20, Jan. 2008, doi: 10.1177/0040517507079781.

[7] S. Sakthivel, B. Melese, A. Edae, F. Abedom, S. Mekonnen, and E. Solomon, "Garment Waste Recycled Cotton/Polyester Thermal and Acoustic Properties of Air-Laid Nonwovens," Adv. Mater. Sci. Eng., vol. 2020, pp. 1-8, Sep. 2020, doi: 10.1155/2020/8304525.

[8] A. G. Temesgen, R. Eren, and Y. Ulcay, "The art of hand weaving textiles and crafting on socio-cultural values in Ethiopian," Int $J$ Adv Multidiscip Res, vol. 5, no. 12, pp. 59-67, 2018.

[9] Z. Ahmed, M. W. Zafar, S. Ali, and Danish, "Linking urbanization, human capital, and the ecological footprint in G7 countries: An empirical analysis," Sustain. Cities Soc., vol. 55, p. 102064, Apr. 2020, doi: 10.1016/j.scs.2020.102064.

[10] R. Ray, "Forgotten Friends: Monks, Marriages, and Memories of Northeast India. By Indrani Chatterjee . New Delhi: Oxford University Press, 2013. xiv, 451 pp. ₹1,025 (cloth).,” J. Asian Stud., vol. 73, no. 3, pp. 832-834, Aug. 2014, doi: $10.1017 /$ S0021911814000862.

[11] S. Adanur, Handbook of Weaving. Boca Raton: CRC Press, 2020. doi: 10.1201/9780429135828.

[12] P. Jain and C. Gupta, “Textile recycling practices in Índia: a review," Int. J. Text. Fash. Technol., vol. 6, no. 6, pp. 21-36, 2016.

[13] O. O. Okpu and O. O. Loromeke, "Comprehensive Drafts of Woven Fabrics," J. Text. Sci. Technol., vol. 06, no. 03, pp. 130-143, 2020, doi: $10.4236 /$ jtst.2020.63011.

[14] A. Ghosh and P. Mal, "Testing of Fibres, Yarns and Fabrics and Their Recent Developments," in Fibres to Smart Textiles, CRC Press, 2019.

[15] M. Kilic, H. K. Kaynak, G. B. Kilic, M. Demir, and E. Tiryaki, "Effects of waste cotton usage on properties of OE-rotor yarnsand knitted fabrics," Ind. Textila, vol. 70, no. 03, pp. 216-222, 2019, doi: 10.35530/IT.070.03.1560.

[16] T. H. Alexander, Sakshi, G. Alka, and G. Manisha, "Quality charaterstics of recycled handloom fabrics," Pharma Innov. J., vol. 9, no. 3, pp. 350-352, 2020.

Publish your research article in AIJR journals-

- Online Submission and Tracking

- Peer-Reviewed

- Rapid decision

- Immediate Publication after acceptance

- Articles freely available online

- Retain full copyright of your article.

Submit your article at journals.aijr.org
Publish your books with AIJR publisher-

- $\quad$ Publish with ISBN and DOI.

- Publish Thesis/Dissertation as Monograph.

- Publish Book Monograph.

- Publish Edited Volume/ Book.

- Publish Conference Proceedings

- Retain full copyright of your books.

Submit your manuscript at books.aijr.org 